\title{
Kajian Teks Naskah Gandoang Wanasigra Sindangkasih Ciamis
}

\author{
Muhamad Mukhtar Zaedin \\ Rumah Budaya Pasambangan Jati \\ mukhtar.rn@yahoo.com
}

\begin{abstract}
Abstrak
Naskah Gandoang adalah naskah yang berada di Wanasigra, Sindangkasih, Ciamis, dan merupakan milik Aki Haji Mahmud. Naskah ini merupakan barang warisan turun temurun dari juru kunci Situs Gandoang. Hingga kedatangan penulis ke tempat itu, naskah ini belum banyak disentuh oleh kalangan. Sehingga kemudian menarik minat penulis untuk membahasnya. Tulisan ini bertujuan untuk mengkaji teks naskah Gandoang dengan mentransliterasikan dan menerjemahkan, serta mengkajinya. Pendekatan yang digunakan adalah pendekatan filologi. Penelitian ini menyimpulkan bahwa Naskah Gandoang adalah salah satu naskah salinan yang memuat nilai sejarah, karena di dalamnya terdapat data rekaman peristiwa yang terjadi pada abad ke-17 berupa surat pengukuhan kekuasaan.
\end{abstract}

Keywords: manuscript, 17th century, Galuh, Imbanegara, Mataram

\section{Pendahuluan}

Manuskrip atau Naskah Kuna adalah sebauah kekayaan intelektual yang berperan sebagai media penyampaian hal-hal yang berkaitan dengan pengetahuan, adat-istiadat, kebudayaan, dan keagamaan yang pada masanya menjadi sebuah pedoman bagi masyarakat penggunanya. Karena, di dalam manuskrip terdapat berbagai ungkapan pikiran dan perasaan sebagai hasil budaya bangsa masa lampau yang masih memberikan informasi menarik dan patut untuk dijadikan bahan 
penelitian oleh berbagai kalangan, terutama kalangan akademisi. ${ }^{1}$ Naskah-naskah Nusantara pada umumnya ditulis dengan menggunakan aksara-aksara daerah yang ada di Nusantara. Naskah daerah merupakan bagian dari naskah-naskah Nusantara. Salah satu daerah yang banyak memiliki naskah adalah Jawa Barat. ${ }^{2}$

Penulisan dan penelitian terkait naskah-naskah kuna akan terus berkembang sejalan dengan berkembangnya minat dan wawasan masyarakat dalam berbagai keilmuan. Naskah-naskah kuna, secara teks dan konteks, bisa didekati dengan berbagai penelitian dan kajian dengan menggunakan berbagai metodenya yang berbeda. Karena, kajian atas naskah-naskah keagamaan tersebut, baik melalui pendekatan filologis, sejarah, atau pun berbagai pendekatan lainnya tak pelak akan memberikan kontribusi sejarah sosial-intelektual Islam di berbagai wilayah dan daerah yang menjadi objek penelitian tersebut. ${ }^{3}$

Naskah menjadi penting manakala sebuah penelitian tentang paham, sejarah, dan kebudayaan tidak bisa diperoleh data yang memadai dilapangan baik dari atrefak, pelaku sejarah, dan hal-hal lain yang berhubungan dengan disiplin penelitian sebuah masalah. Karenanya penelitain dan kajian ini dilakukan untuk mendorong para akademisi agar melirik ke arah sumber asli yang otentik yang masih tersebar di tengah masyarakat. ${ }^{4}$ Model penelitian dan kajian naskah ini tentunya merupakan sebuah kontribusi penting, tidak saja dunia filologi sendiri melainkan bagi dunia akademik secara keseluruhan. Bahkan, tidak berlebihan kiranya kalau pendekatan fililogis yang disertai dengan analisis sejarah sosialintelektual Islam ini akan menjadi semacam trend, khusunya di kalangan

${ }^{1}$ Elis Suryani Nani Sumarlina,. Filologi. Bogor: Ghalia Indonesia, 2012, h. 7.

${ }^{2}$ Edi S. Ekadjati, Naskah Sunda : Inventarisasi dan Pencatatan, (Bandung: Universitas Padjajaran, 1988).

3 Azyumardi Azra, dalam Oman Fathurahman, Tarekat Syattariyah di Minangkabau, Jakarta: Prenada Media Group, 2008, h. 9.

${ }^{4}$ Elis Suryani Nani Sumarlina,. Filologi ...., h. 7. 
mahasiswa dan para peneliti Perguruan Tinggi Islam semisal Universitas Islam Negeri (UIN) atau Institut Agama Islam Negeri (IAIN), seiring dengan semakin terbukanya informasi keberadaan naskah-naskah keagamaan Nusantara melalui penyusunan katalog naskah dan minat kajian Islam lokal Indonesia. ${ }^{5}$

Pada saat menguraikan teks yang ada dalam naskah, naskah dan teks sering dipertukarkan secara serampangan oleh sebagian orang yang tidak bisa memahami antara teks dan naskah sehingga pembahasan menjadi sulit dicerna. Mereka masih beranggapan bahwa teks adalah naskah itu sendiri, atau dengan kata lain bahwa naskah sama dengan teks. Menurut Oman Fathurrahman, jika naskah merujuk pada bundel fisik dokumen kuna yang sedang kita diskusikan, maka teks adalah apa yang terkandung di dalam dokumen (naskah) tersebut, yang teks kandungan isinya itu bisa sama dengan yang ada dalam dokumen yang lain, baik di wilayah Ciamis, Cirebon, atau pun di daerah lainnya, sebagian atau keseluruhannya. ${ }^{6}$ Artinya, satu teks yang sama bisa saja ada pada beberapa naskah yang berbeda dalam wilayah atau pun tempat yang berbeda. Hal ini tidak aneh ketika melihat teks al-Quran yang bersebaran di seluruh dunia. ${ }^{7}$ Hal itulah yang terjadi dalam Naskah Gandoang ini.

Untuk tahap pertama penelitian naskah ini dibatasi pada identifikasi naskah atau deskripsi naskah, alih aksara, alih bahasa, dan kajian singkat isi naskah. Naskah ini ditulis dalam bentuk prosa dan ditulis dalam huruf Jawa (Cacarakan). Dalam proses pengerjaan ini, pertama kita mengalihaksarakan (transliterasi) dengan pemindahan aksara dari huruf Cacarakan yang ada dalam naskah asli ke aksara latin yang baru yang dapat dibaca oleh semua orang. Sementara ini kita

5 Azyumardi Azra, dalam Oman Fathurahman, Tarekat Syattariyah di Minangkabau, Jakarta: Prenada Media Group, 2008, h. 10.

${ }^{6}$ Oman Fathurrahman, dkk., Filologi dan Islam Indonesia, Jakarta: Kemenag RI Badan Litbang dan Diklat Puslitbang Lektur Keagamaan, 2010, h. 6.

7 Teks merupakan sebuah tema yang ada dalam satu naskah, bahkan satu naskah bisa memiliki beberapa teks yang berlainan temanya.

137 | TamaddunVol. 7 , No. I, Januari - Juni 2019 
belum melakukan koreksi atas tulisan (teks) naskah aslinya belum dilakukan. Artinya kita hanya menyajikan bunyi teks aslinya dengan tanpa memberikan kritik teks sebagaimana mestinya. Dalam menerjemahkan (alih bahasa) teks naskah dari bahasa naskah (bahasa Jawa) ke dalam bahasa Indonesia dilakukan dengan terjemahan maknawiyah, yaitu mengungkapkan kandungan maksud dari teks naskah tersebut. Atau denga kata lain, penerjemahan yang kita lakukan menggunakan penerjemahan bebas yang tidak terikat dengan secara harfiyah. Namun demikian, masih terdapat beberapa kata yang diterjemahkan secara harfiyah. Dalam arti, teks naskah diterjemahkan dalam susunan bahasa yang mendekati teks aslinya. Dalam laporan ini dilampirkan pula teks naskah aslinya dalam bentuk (data) digital sebagai kelengkapannya.

Penelitian ini dilakukan dengan menggunakan pendekatan studi filologi. Karena kebanyakan penelitian naskah masih bersifat filologis, yaitu dengan mentransliterasi, menerjemahkan dan mengkaji naskah. Pendekatan ini dimaksudkan untuk mengindentifikasi naskah secara filologis dan mengungkap isi teks naskah yang tersimpan didalamnya. Dalam mengedisi naskah dilakukan dengan menggunakan metode edisi standar, yaitu melakukan perbaikan atau meluruskan teks, sehingga terhindar dari kesalahan dan penyimpangan yang timbul ketika proses penulisan. Tujuannya untuk menghasilkan edisi naskah melalui pembuatan alinea, pungtuasi, (tanda grafis yang digunakan secara konvensional untuk memisahkan berbagai bagian dari satuan bahasa tertulis atau tandabaca), membuat huruf besar dan kecil, dan penafsiran kata yang perlu penjelasan.

\section{Deskripsi dan Ringkasan Isi Naskah Kabuyutan Gandoang}

\subsection{Deskripsi Naskah}

Penetapan nama naskah ini dengan nama Naskah Gandoang dikarenakan di dalam teks naskah tidak ditemukan judulnya, sehingga nama Naskah Gandoang 
disematkan kepada naskah ini. Hal itu karena naskah ini ditemukan di Kebuyutan Gandoang. Sayangnya tidak ada naskah pembanding atau naskah lain yang ditemukan di tempat ini atau di sekitar wilayah Gadoang untuk memperkirakan nama penulis atau penyalin naskah. Namun demikian, dari segi kalangan dan kelas masyarakat penulis naskah, kita bisa memperkirakan bahwa naskah ini ditulis oleh seseorang yang ada kaitannya dengan sejarah kekuasaan dan politik di Ciamis Galuh. Dan pada halaman 12 terdapat kalimat: "hamba bernama Ki Milu, yang mengawi (menggubah) Cerita Rasul. Oleh karena itu disusunlah cerita yang dilantunkan dengan tembang kidung." Itu artinya bahwa teks naskah Gandoang dibagian akhir yang berisi cerita Rasul Muhammad SAW - termasuk juga silsilahnya - adalah Ki Milu. Sayangnya hingga laporan ini disusun, kita belum mendapatkan penjelasan sedikit pun tentang siapa sosok yang bernama Ki Milu itu sebenarnya. Identitasnya belum terang.

Total halaman Naskah Gandoang ini jumlahnya sebanyak 35 halaman isi dan 2 halaman kosong. Adapun ukuran fisik naskah selebar 15,5 x 12,2 cm. Sedangkan luasan ukuran teksnya adalah $12 \times 9 \mathrm{~cm}$. Jumlah baris teks pada tiap halaman dibagian depan sebanayak 10 baris dan beberapa halaman akhir berisi 6 baris. Naskah Gadoang ini tidak menggunakan kata alihan yang berfungsi sebagai pengikat halaman selanjutnya. Naskah Gandoang ini juga tidak memiliki nomor halaman yang asli. Namun demikan, ada nomor halaman yang berada di bagian atas tengah dengan angka latin berwarna merah yang tampak terlihat baru. Halaman itu merupakan penomoran halaman yang ditambahkan kemudian.

Bahasa yang digunakan dalam teks Naskah Gadoang ini adalah bahasa Jawa. Dan aksara yang digunakan adalah Aksara Jawa (Cacarakan). Jenis bahan naskah (alas naskah) menggunakan kertas daluwang yang terlihat sudah berwarna coklat kehitaman. Adapun kondisi fisik Naskah Gandoang ini sudah rusak. 
Beberapa halaman, baik di halaman depan, tengah, maupun halaman akhir sudah terlihat banyak yang berlubang karena termakan ngangat. Ada beberapa halaman yang robek, tulisan agak samar dan ngeblur. Jika dilihat dari ketebalan tinta dan bentuk karakter aksara yang digunakan dalam penulisan teks, Naskah Gadoang ini sepertinya tidak ditulis oleh satu orang.

Adapun isi teks Naskah Gadoang ini berbicara tentang surat (layang, nawala) yang ditulis oleh Susuhunan Senapati Ing Ngalaga kepada Mas Putu atau Mas Putra Imbanagara agar menduduki, memangku, dan mengurusi Galuh (gaduhi bumi galuh (hlm.02), yang memiliki wilayah Galuh). Selanjutnya teks Naskah Gandoang ini membahas tentang silsilah Nabi Muhammad SAW yang menjadi kewajiban bagi umat islam, baik laki-laki maupun wanita. Silsilah tersebut diceritakan hingga sampai kepada Nabi Adam AS. Dengan pembahasan yang agak panjang, naskah ini juga menjelaskan tentang nur muhammd yang berpindah dari Nabi Adam AS hingga Abdulllah ayah dari Nabi Muhammad SAW.

Layaknya sebuah naskah yang lengkap dan utuh, naskah ini memuat sebuah titi mangsa (penanggalan) atas sebuah penulisan layang (surat) yang dikirimkan oleh Susuhunan Ing Ngalaga kepada Mas Putra Imbanagara. Titi mangsa itu berbunyi: kala angaturi layang ing dina kemis tanggal ping tiga sasih sawal tahun he. Titi. (hlm. 05). Apabila titi mangsa pengiriman surat itu diterjemahkan dengan bunyi: ketika mengirimkan surat ini pada hari kamis tanggal 3 bulan syawal tahun he, maka periode waktunya dapat diterjemahkan. Jika kita konversikan ke dalam tahun Masehi, maka hari kamis tanggal 3 bulan Syawal tahu He itu jatuh pada tanggal 22 Maret 1635.

\subsection{Ringkasan Pembahasan Teks}

Dibagian akhir naskah ada semacam penjelasan bahwa yang menulis naskah ini - walapun hanya menyebutkan di Carita Rasul juga silsilah Nabi 
Muhammad SAW - adalah seseorang yang bernama Ki Milu. Adapun Titi Mangsa "hari kamis tanggal 3 bulan syawal tahun he" yang dikonversikan ke dalam tahun Masehi bertepatan dengan tanggal 22 Maret 1635 sebenarnya adalah bunyi surat yang dikirimkan oleh Susuhuan Ing Ngalaga kepada Mas Putu Imbanegara. Artinya naskah ini merupakan data salinan dari surat itu mengingat bahwa surat resi kerajaan biasanya dibubuhi dengan tanda tangan dan cap stempel. Siapakah Mas Putu Imbanagara yang ditunjuk oleh Susuhunan Ing Ngalaga dalam surat itu? Dalam silsilah Galuh naskah Cirebon, Imbanagara ditulis sebagai keturunan dari beberapar Raja Sunda dan Galuh yang terkenal seperti Prabu Wastu, Prabu, Susuk Tunggal, Prabu Hanggalarang, dan lain-lain.

Dari silsilah ini, diketahui pula bahwa Adipati Ambanagara menurunkan Raden Adipati Arya Panji Prabu Jayanagara, kemudian Raden Adipati Arya Panji Prabu Jayanagara menurunkan tiga orang putra: 1) Raden Ayu Galuh, 2) Raden Ayu Angganata, dan 3) Dalem Arya Anggapraja. Ketiganya ini bisa dikatakan sebagai cucu (bahasa jawa: putu, seperti yang terbaca dalam naskah Gandoang) dari Imbanegara. Adapaun Raden Adipati Arya Panji Prabu Jayanagara bisa disebutkan dengan istilah Putra Imbanegara.

Selanjutnya kita lihat data tahun dari para penguasa yang pernah memerintah di Galuh / Ciamis pada tahun 1800 hingga 1900. Dari tulisan yang pernah ditulis oleh beberapa sejarawan - salah satunya adalah Nina Lubis - bahwa pergolakan politik dan penguasa terjadi di wilayah Galuh pada abad ke-17, terutama setelah terjadinya perintah penyerangan terhadap Batavia dan pemberontakan Dipati Ukur terhadap Sultan Agung.

Titi mangsa surat dari Susuhunan Ing Ngalaga yang ditunjukkan kepada Mas Putu Imbanagara yang jatuh pada hari Kamis tanggal 3 bulan Syawal tahun $\mathrm{He}$ yang bertepatan dengan tanggal 22 Maret 1635, maka nama itu adalah wajar 
mengingat catatan sejarah menyebutkan bahwa: "Dalam perselisihan kekuasan di Galuh, Adipati Panaekan terbunuh tahun 1625 oleh Dipati Kertabumi yang tengah menjabat sebagai bupati Bojonglopang. Ia kemudian diganti puteranya Mas Dipati Imbanagara yang berkedudukan di Garatengah (Cineam sekarang)". Artinya pada rentang waktu beberapa tahun kemudian baru ada ketetapan, ketentuan, dan aturan dari Susuhunan Ing Ngalaga sebagai atasan dari Mas Adipati Imbanegara tentang masalah-masalah wilayah yang dapat dikelola, diawasi, dan atau dikuasai oleh Mas Adipati Imbanagara.

Sebenarnya pengirim surat dalam naskah Gandoang adalah tiga, yaitu: Eyang Raja Desa, Eyang Wiranangga, dan Susuhunan Senapati Ing Ngalaga. Surat dari Susuhunan Senapati Ing Ngalaga ditunjukkan kepada Sang Asar yang isi surat itu menegaskan tentang kekuasaan Sang Susuhunan atas bumi Galuh. Adapun surat dari Raja Desa dan Eyang Wiranangga ditunjukkan kepada Mas Putu (Putra) Imbanagara yang berisi penyerahan tanah dan wilayah sekitar 29 tempat. Surat dari Raja Desa (mungkin juga Eyang Wiranangga) itu berbunyi:

"Memberikan tanah ladang keduanya kepada Ki Mas Imbanagara. Tanah atau negara sejumlah 29 [dua puluh sembilan] dikuasakan kepada Ki Imbanagara. Negara Tengah, Pasir Panjang, Cijoho, Lokasana, Cipede, Sindang Kasih, Sidangla, Ciparaiy, Pamotan, Manonjaya, Ciloweh. Adapun tanah yang dibagi ...... (korup) yang ada [diberikan] kepada Kyai Sutanangga, (yaitu tanah); Kawasen, Cibodas, Geger, Ciamis, Citambal, Litung Maung, Surupan. Ngawotan Kyai Singa Prabangsa, alam marapatan; Bengkok Labangan, Tirta Kumalang, Kertabumi, Tembong Gunung, Pangrayaman. Yang berada pada Kyai Raja Desa; Bojong Galuh Utama, Panamun, Rimpak, Leuwi Bingur, Lesir. Demikianlah yang dikuasakan kepada Kyai Mas Imbanagara, yang dipanggil disuruh membagi wilayah. Titik. (hlm. 06-08)." 
Akan tetapi titi mangsa (penanggalan) dari ketiga surat tersebut adalah satu, yaitu hari Kamis tanggal 3 Syawal tahu He yang bertepatan dengan tanggal 22 Maret 1635.

\section{Alih Aksara dan Bahasa Naskah Kabuyutan Gandoang}

Sebelum memasuki translitrasi atau alih aksara, maka sebelumnya kami akan memberikan beberapa penjelasan tanda-tanda yang kami gunakan dalam translitrasi dan terjemahan naskah ini, bahkan di naskah-naskah yang kami kerjakan.

1. Tanda angka atau nomor yang ada di dalam tanda "()" itu berarti adalah nomor halaman naskah.

2. Angka atau nomor yang tidak ditandai dengan kurung buka dan kurung tutup "()" itu merupakan nomor urut dari baris tulisan yang ada di dalam halaman naskah.

3. Tanda garis miring satu "/” itu merupakan penyalinan dari Padalungsi yang dalam aksara latin hampir sama (sebenarnya tidak bisa disamakan) dengan koma.

4. Tanda garis miring dua "//" itu merupakan penyalinan dari Padalingsa yang dalam aksara latin hampir sama (sebenarnya tidak bisa disamakan) dengan titik.

5. Tanda “. (korup)" itu artinya bahwa aksara yang ada dalam baris itu telah rusak dan tidak dapat dibunyikan lagi.

6. Tanda tanya "?" itu merupakan pembacaan yang kami masih meragukannya karena kalimat yang ada pada baris itu terasa tidak nyambung dengan baris sebelumnya atau sesudahnya.

Selanjutnya marilah kita ikuti hasil translitrasi atau alih aksara yang sudah kami kerjakan. Selamat membaca. 


\subsection{Alih Aksara}

(02)

1. (korup) nawalaningsun

2. susuhunan senapati ing

3. ngalaga // gaduh dening sangasar/mar-

4. gane gaduh nawalanisun / si-

5. ngangsar sun gaduhi bumi galuh

6. ratune satetes lemahe sa-

7. kilungsu / iku sing ngangsar kang agaduwe //

8. dene wong ratu wong rongewu sanga-

9. ngatus sawidak // sapa mahi dé

10. wa hi .........(korup) saka (korup)

(03)

1. saraha ing ngarep (tulung)

2. layang saka

3. (patanda) na-

4. ma miwah bumi lawan langa(ngit)

5. yyang téki mi..... (korup)

(04)

1. punika (éyang) pun néyang wira nangga arya pun

2. pama luwih ratu emas putu i-

3. mbanagara // pun eyang anarima yen

4. kasisipan i mangke sumangga i kar-

5. sa / pun eyang gungan // bala angatura-

6. ken layang ing dina kemis tanggal p-

7. ing tiga sasi sawal tahun he // ti- 
8. ti // punika layang pun eyang wi-

9. ragayang pama leuwih katura dateng

10. mas putu imbanagara pun eyang ana(05)

1. rima yen mangke kasisipan // ing mangke

2. sumangga ingkang karsa / pan ikang a-

3. ran // kala angaturi layang ing di-

4. na kemis tanggal ping tiga / sasih sa-

5. wal tahun he // titi //

6. punika layang pun eyang raja desa

7. ngatur dateng mas putu imbanagara //

8. pun eyang anarima yekasisipan

9. i mangke sumangga ingkang karsa / pan i-

10. kang kagungan // kalana aturi layang (06)

1. ing dina kemis tanggal ping tiga sa-

2. si sawal tahun he // titi //

3. penget siti gaga duwanipun

4. ki mas imbanagara // siti kalih dasa

5. sasanga watanipun ki imbanagara

6. // nagara tengah / pasir pa(n)jang / cijoho

7. / lokasana / cipede / sidang(k)asih / si-

8. sidangla / ciparaiy / pamotan / mano-

9. njaya / ciloweh // pidani siti

10. pinarapat // ............ kang wo(n)ten i 
1. kiyahi suta nangga // kawasen / ci-

2. bodas / geger / ciamis / cita-

3. mbal / litung maung / surupan // nga-

4. wotan kiyahi singa prabangsa //

5. alam marapatan // bengko-

6. k labangan / tirta kumalang /

7. kertabumi / tembong gunung // pangra-

8. yaman // kang wo(n)teni kiyahi ra-

9. ja desa // bojong galuh / utama

10. panamun rimpak bingur leuwi (08)

1. lesir // \# // punika ikang angarapan

2. kiyahi mas imbanagara // kang

3. katimbalan kinanamarapat

4. // titi //

5. Punika tutur luhur a(n)dika rasululla-

6. h ikang luhur // parlu angawikani

7. sakehe wong islam lanang lan islam wa-

8. don sawabé hikang hangawika-

9. ni / hutawi nabi muhamaddika / i-

10. kang rama anaki hadhulah // adhulah

11. ki adulmatalib anak ki rabiga-

12. lib / nabi ..... saking kanghar/ ma-

13. har // anak malik hiku

(09) 
1. ki nat ki tapsir / hanak ki nadah / nadah

2. hiku anak ki jihu ma dallinah i-

3. ku nak ki mukalihap ..... ki

4. malu / ku anak ki najid iku

5. anak ki malam iku ana-

6. k ki / pahur iku anak ki parag

7. iku anak ki yasjab iku a-

8. nak ki sabit anak ki bagidhais

9. nyahima bab nyahim miku

10. hanak ki pijar / pijar hiku / ha-

11. nak ki pahar / hanaki saro / sa-

12. ro hiku hanak ki ajir / hanak ki

13. salih / hanak ki palabah / pala(10)

1. anak ki samsam anak ki

2. agaridha / anak ki mala-

3. m malam anak ki rasula /

4. rasula / anak ki bagadais

5. iki / anak ki masar / masar a-

6. nak ki malim mika / malik

7. anak ki rakad / anak ki yad yad

8. anak ki adam alahéslam //

9. punika carita luluhur nabi agung

10. sawabbé / pitung watara pinadaka-

11. ken watu jungi hika batullah

12. ping séwu / lan pinadakaken wa- 
(11)

1. tu jungi hing madinah / ping séwu / lan

2. pinadakaken amaca tigapuluh

3. juma ping séwu / lan pinadakaken

4. lan wong serasatil ping sé-

5. wu / pinadakaken / wong

6. sideka hemas lir sagunung /

7. ping séwu / lan lam nagering ra-

8. n dumadak waras / lah mupaté-

9. né dumyadak pada / tamman /

(12)

1. tyang té ki milu

2. angawi carita rasul ginni-

3. tya marmanning ginurit mangko

4. carita kidungan tembang

(13) (halaman kosong)

(14)

1. tyang té ki

2. milu angawi carita

3. rasul ginitya marmaning ginu-

4. rit mangko carita kidungan

5. tembang-tembang asmarandanna

6. téngsun nangrung-

(15)

1. ngu tutur nbi rasul lika // 
2. lewih becik mangki-

3. n kang carita lyan nika

4. kocapping jro sastra mang-

5. ko rasullullah lewih mu-

6. lya sakéhén nabinning

(16)

1. yyang anging rasul lewih ika kang

2. tinut re ing jagat // ya-

3. yah hangréh ya ahmaduna

4. sa lyir kumilip punika sa-

5. king rasul pinangkané pangu-

6. lunning nyawa hika pannakékatting

7. jagat tan lanna handika rasul

8. yahiku kakasih hing yyang // mi-

9. wah bumi lawan langit pan naweta-

10. ra ki muhamad wulan lan sra

11. ngéngé mangko lintang kalawa-

12. $\mathrm{n}$ tan méga muwah luhkalam lan

(17)

1. aras kursi tan lyan niku sa-

2. king roh hilapi ika //

3. malékat lan hiblis hejim pe-

4. ri parayangan saking muhamad ta mang-

5. ko yéku dalilé halya

6. muka kalayyan nabi kalya panu-

7. tubing nnabi rasul ngangkenya 
8. gaganti yyang sukma // purwakani-

9. kang winarni pratimah samangko

10. ..... (korup) tri adi jagat mangko ha-

11. matur bakti yyang sukma / tanantara

12. winarni rawu jinnira hing yyang ngagung

(18)

1. kala waktu asabahyyang // ta-

2. npatara pujinéki yén si-

3. yang puasa rekéh tan pegat tri-

4. lat mangko saya sru wedi hyang

5. sukma miwah asih ing bala a-

6. nnak yatim pakir riku / ki-

7. nnasihyan dén sannata // ta-

8. n pegat dananni réki toya

9. mili ika kasuksra ing jagat sa-

(19)

1. mpun gada polat tingka pinarek pa-

2. ra hemban para hinyanya haglar riku

3. hing jawi ....... // kang putri ha-

4. ngandika haris babu hinyah marénna

5. ...... guna wowohan mangko ka-

6. ya hingsun hasambahyang tininga-

7. laken wahyu kaya wulan pur-

8. naméku / kaliwat hasru hapa-

9. dang // sampun haningali singgi

(20) 
1. ing tyang ammidenger syara ujaring

2. syara ta mangko héh prati-

3. mah sammi sira singa madahanna

4. cahyya ingkang tumedakkiku su-

5. n panjingaken ning sya // cahyya

6. ta punniku nninni annéng batu-

7. kking ngabdullah annakké kang prabu mang-

8. ko ing mandinah rekéh ika a-

9. bdul muttallibbika kaya putra li-

(21)

1. lima iku / abdullah kang tuwa

2. ika // kang panggulu abu tallib

3. abas panengah yé ika mé-

4. nnak amjyah wurujunné wu-

5. ragil histri punika suraté-

6. nniki ...... manira puninyah mang-

7. ké humatur / singgih ta punapa

8. radyan // sang putri ngandika

9. mallih hinyanya mangké karsan ning

(22)

1. wyang ya hamarling ngabdulah hayu-

2. n madinah mangko hangunggahi

3. karsan ning ngyang / hanglamar hing ngabdullah

4. malar hangandut waténgsun cahyya

5. kang tumedak kika // hinyah

6. katara hanniniba lakénni 
7. samya dadan gagaman lawan sang ngu-

8. ndé budal mangko karsan ning ngyang /

9. hinyah sira dangdana / raja

(23)

1. kaputra niréku gawanne-

2. n kabéh dénnira // emas

3. nnayakan niréki / kalpi ka-

4. lawan gegelang kilat bahu na-

5. ga kuwé kang kalung inten wi-

6. duryyan mirah lan mutyaha-

7. ra cucundukkan sekar suhu-

8. n suweng lawan nyamtra pélag

9. // sampunya sawara aglis kawu-

(24)

1. la bala adan puninyah hu-

2. matur mangko sampu(n) sayaga kang

3. bala punapa karsa tuwan ha-

4. budal sang prabu / ha-

5. nnitih jampanna hemas //

6. ginarebeg bala néki

7. wong dalem lan para emban ..

8. ....... lap ika ta mangko ra-

9. ré wungkuk raré wadon

1. pun bulé punika kathah ha-

2. mantri nipun lumampa ngarsa 
3. hawuntat // samyan nitih ku-

4. da asri miwah .......

5. .... atrang tinningalan mangké

6. gagaman ning sahidinna lyir sekar

7. salasi rada tan kawarnna héng nge-

8. nuh aglis prapta ing madinna

9. amondok jawininng kori

(26)

1. katur ring sayadina sang nata

2. putri handika mangko babu hi-

3. nya marénéya sun kongkon

4. naglis sira dateng nging jro kitha

5. iku / mareking narténg madinah

6. // matura mangké siréki yén

7. nisun narsa kang putra hangunggah

8. hannawa mangko ngabdullah punni-

9. ka poma matura huga puninyah

(27)

1. hamit pukulun haglis rawuhé

2. pun ninya // hamit ta nembah .... (korup) ré-

3. ki pun ninyah lumampah sahéngga-

4. 1 prapténg panangkilan / mangko ha-

5. natanarek sira matur pun babu hi-

6. nnyah kawula ngutus punika/

7. yun dénning putri sayidinna //

8. sang prabu putran niréki hi- 
9. ku mangké / hing ngunggah lan dénnira (28)

1. gusti .... (korup) hamangko kang nnama

2. ..... (korup) bdulah dadya ling ngira sang

3. nata ..... (korup) namané pu nika / hing

4. kang ngarsa hanaking wang // pun ninyah

5. matur siréki pratimah sammi na-

6. manya sang nata ngandika mangko ha-

7. bdullah hanak manira nanging sam-

8. pun kanakrama tan patut

9. ta rabi nipun hélik mantunni

10. punika // hang manah haran déwi (29)

1. ki ... (korup) ngiku pagar ...... (korup) kadya la-

2. mining apanggih mangké hamiharsi ha-

3. nahing tan hanakisun habdullah

4. yé si mangko siréku maraha

5. sira hing taman // hamat hanem-

6. bah siréki dadya sira

7. maring taman pun ninyah lumam-

8. pah hagé lengak nata sira sang ngya-

9. ten ning jro taman abdullah mang(30)

1. ké winu (korup) 1 mangké cahya ni-

2. ra // (korup) singngling puniki warna

3. nira lir pawaka kalanning purnama 
4. padang gumawang kadya nnawang ma-

5. ncorong kadya lidah mantur

6. gara lyir ranarung / kaya gurnitya

7. gumebyar // suram kang surya

8. sari kasileyan déning cah-

9. yya nurbuwat mangké ika jro

10. da (korup) hapadang mangko kakelnye-

(31)

1. nahhi // hanéng (korup)

2. (korup)

3. (korup)

4. (korup)

5. dah hena (korup) hingkang (korup)

6. (korup) kenang

7. syar (korup) //

8. (korup)

9. (korup)

(32) (korup)

(33) (korup

(34)

1. hing jeng ngandika hing (korup)

2. (korup)

3. (korup)

4. (korup)

5. (korup) 

6. (korup)
7. (korup)
8. (korup)
9. (korup)
10. (korup)

(35)

1. putri adi midera séng nagara mangkin

2. (korup) kaya sira // kaya widada

3. (korup) hing mana (korup)

4. (korup)

5. (korup) sekar (korup)

6. (korup)

7. (korup)

8. (korup)

9. (korup)

10. (korup)

\subsection{Alih Bahasa}

(02)

Surat dari Aku, Susuhunan Senapati Ing Ngalaga, diberikan kepada Sangasar. Sebab Aku mempunyai (membuatkan) surat ini, Sangangsar Aku diberi kuasa (mempunyai) atas Bumi Galuh. Ratunya setetes tanahnya sebesar biji asem (kelungsu), itulah Sangangsar yang berhak memiliki.

Adapun ia berkuasa atas 2.960 (dua ribu sembilan ratus enampuluh) orang, diberikan kuasa dari dewa (penguasa yang lebih tinggi) dari 
(03)

Bagi siapa saja yang hendak memberikan bantuan, Surat dari Patanda (Pecattandha) nama serta bumi dan langit. Berasal dari Hyang (tuhan) .......

Aku adalah Eyang Wiranangga, pun paman memberi kepada Ratu Emas Putu Imbanagara. Maka eyang menerima kesalahan, oleh karena itu eyang meyerah terhadap segala kehendakmu. Eyang memiliki pasukan, menghaturkan Surat ini pada hari Kamis tanggal 3 bulan Syawal tahun He. (tanggal 22 Maret 1635). Titik. Itu adalah surat dari Eyang Wiranangga, menghaturkan kepada Mas Putu Imbanagara. Eyang menerima

bahwa telah melakukan kesalahan. Oleh karena itu eyang menyerah terhadap segala kehendakmu. Tatkala menghaturkan Surat ini pada hari Kamis tanggal 3 bulan Syawal Tahun He. (titi mangsa)

Surat ini adalah dari Eyang Raja Desa, menghaturkan kepada Mas Putu Imbanagara. Eyang menerima kesalahan, oleh karena itu menyerah terhadap segala kehendakmu yang mempunyai kekuasaan. Tatkala menghaturkan surat (06)

Pada hari Kamis tanggal 3 Bulan Syawal Tahun He (tanggal 22 Maret 1635). Titi. Memberikan tanah ladang keduanya kepada Ki Mas Imbanagara. Tanah atau negara sejumlah 29 (dua puluh sembilan) dikuasakan kepada Ki Imbanagara.

Negara Tengah, Pasir Panjang, Cijoho, Lokasana, Cipede, Sindang Kasih, Sidangla, Ciparaiy, Pamotan, Manonjaya, Ciloweh.

Adapun tanah yang dibagi..... (korup) yang ada (diberikan) kepada (07) 
Kyai Sutanangga (ialah) Kawasen, Cibodas, Geger, Ciamis, Citambal, Litung Maung, Surupan.

Ngawotan Kyai Singa Prabangsa, alam marapatan, Bengkok Labangan, Tirta Kumalang, Kertabumi, Tembong Gunung, Pangrayaman.

Yang berada pada Kyai Raja Desa (seperti) Bojong Galuh Utama, Panamun, Rimpak, Leuwi Bingur,

Lesir.

Demikianlah yang dikuasakan kepada Kyai Mas Imbanagara, yang dipanggil disuruh membagi wilayah. Titik.

Ini adalah cerita luhur sabda Rasulullah yang luhur, "Wajib mengetahui bagi semua orang Islam laki-laki dan perempuan." Sangat berfaedah bagi orang yang mengetahui, adapun Nabi Muhamad adalah putra dari Abdullah.

Abdullah putra dari Abdul Muthalib putra dari Rabigalib. Nabi dari Kanghar, Mahar putra dari Malik.

Ki Nat Ki Tapsir putra dari Ki Nadah, putra dari Jihu Ma Dallinah, putra dari Ki Mukalihap, putra dari Ki Malu, putra dari Ki Najid, putra dari Ki Malam, putra dari Pahur, putra dari Ki Parag, putra dari Yasjab, putra dari Ki Sabit, putra dari Ki Bagidhais Nyahim(a).

Mengenai Nyahim putra dari Ki Pijar, putra dari Ki Pahar, putra dari Saro, putra dari Ki Ajir, putra dari Ki Salih, putra dari Ki Palabah, putra dari

Ki Samsam, putra dari Ki Agaridha, putra dari Ki Malam, putra dari Rasula, putra dari Ki Bagadais, putra dari Ki Masar, putra dari Ki Malim(k), putra dari Ki Rakad, putra dari Ki Yadyad, putra dari Nabi Adam As. 
Demikianlah cerita leluhur daripada Nabi (Muhamad Saw) sangat besar faedahnya. Diantara tujuh keutamaan ialah ; dianjurkan mengunjungi Ka'bahtullah seribu kali, dianjurkan

mengunjungi Madinah seribu kali, dianjurkan membaca tigapuluh (jenis ayat/dzikir) seribu kali, dianjurkan bagi orang serasatil seribu kali, dianjurkan sedekah emas seperti sebesar gunung seribu kali (menghilangkan rasa cinta emas). Dan jika ada orang yang menderita sakit akan menjadi sembuh, demikianlah manfaatnya bisa menjadikan (menghantar tujuan)

Hamba bernama Ki Milu, yang me-ngawi Cerita Rasul. Oleh karena itu disusunlah cerita yang dilantunkan dengan tembang kidung.

(13) (halaman kosong)

Hamba bernama Ki Milu, mengawi Cerita Rasul. Oleh karena itu disusunlah cerita yang dilantunkan dengan tembang kidung Asmarandana. Hamba telah mendengar

Tentang cerita Nabi Rasulullah yang lebih baik dari cerita lainya. Telah dituturkan dalam sastra tulisan bahwa Rasulullah lebih mulia daripada semua para nabi

Allah, hanya Rasulullah yang diberi kekuasaan atas jagat raya. Ialah berkuasa atas isi dunia, dari rasul yang menjadi panguluning (pendahulu/cikal bakal) daripada nyawa. Rasulullah adalah hakikat dari jagat yang merupakan kekasih dari Allah Swt. Bumi langit, bulan matahari, bintang dan mega, serta Lohkalam 
Arsy, Kursi itu semua berasal dari Ruh Ilafi. Demikian juga malaikat, iblis, jin, peri parayangan berasal dari (hakikat Nur) Muhamad. Itu semua terdapat dalam sabdaNya, Rasulullah adalah Nabi Penutup daripada nabi-nabi. Kanjeng Rasulullah mengakui sebagai pengganti (wakil) dari Hyang Sukma (Allah).

Berawal dari cerita Pratimah tatkala menghaturkan sembah bakti / sembahyang kepada Hyang Sukma (Allah). Tidak begitu lama kemudian datanglah Jin / Utusan dari Hyang Agung

Tatkala bersembahyang, melakukan puji-pujian terus-menerus. Jika siang berpuasa tak putus juga melakukan riadhoh, sehingga semakin kuat saja rasa taqwa kepada Hyang Sukma serta rasa kasih sayang kepada para anak yatim pakir miskin. Mengasihi mereka dengan sebenarnya, maka tidak akan diputuskan dari rizki. Malah dianugahi rizki bagaikan air mengalir, begitulah keadaanya.

Sedang dihadap oleh para emban, para inya. Mereka berkumpul di sana, di luar ..... Sang putri berkata, "Wahai Babu Inya, kemarilah carilah jenis buah-buahan seperti tatkala terlihat diwaktu aku sedang shalat. Rupanya bercahaya bagaikan bulan purnama yang sangat terang sekali. Aku melihatnya dengan benar/nyata,

Kemudian mendengar suara, menurut suara itu, "Hei Pratimah, hendaklah kamu mewadahi cahaya yang bergerak itu. cahaya itu Aku telah masukan kepada seseorang. Wahai Pratimah, cahaya itu telah berada di dalam dahi Adbullah putra dari Raja Madinah. Ia adalah Abdul Muthalib yang mempunyai 
lima orang putra, yang pertama Abdullah. Putra panggulu (kedua) Abu Thalib, putra panengah Abas, Menak Amjyah dan putri bungsu.” Inya (Dayang) menerima sabda perintah, kemudian sang putri berkata lagi, "Wahai Inya, aku ingin

melamar Abdullah Madinah itu agar mau bersanding denganku. Dengan maksud agar kelak aku bisa mengandung dari orang yang mempunyai cahaya terang yang bergerak itu." Para Inya kemudian memanggil suaminya (prajurit). Mereka segera berkemas lengkap dengan senjata. Sang putri memerintahkan agar

mereka (Inya-Babu) membawa semua putranya untuk membawa ; emas, nayakan, kalpika, gelang kilat bahu naga, kalung inten, widuri, mirah, mutiara, tusuk konde kembang suhun suweng, dan nyamtra bagus. Benda-benda mulia itu merupakan bahan lamaran. Setelah semua kawula bala siaga

Kemudian Sang Inyah menghatur, "pasukan telah siaga untuk memenuhi karsa tuan putri." Maka pergilah sang ratu dengan naik jempana (tandu) emas dengan diiring oleh pasukan. Barisan para abdi dalem, para emban, bocah bungkuk, bocah perempuan,

bocah bule. Banyak para mantri berjalan di depan dan di belakang, mereka samasama menunggang kuda yang bagus dan perkasa. Barisan prajurit terlihat rapat teratur indah, pusaka milik Sayyidina terlihat bagaikan kembang selasih bercahaya seperti prada gemerlipan. Tidak diceritakan diperjalanan, syahdan barisan sang putri telah tiba di Madinah membuat pondokan diluar kori/pura. 
Dihaturkan kepada Sayyidina, sang raja putri berkata, "Babu Inya kemarilah! Aku menyuruhmu supaya cepat pergi ke dalam kota. Pergilah kehadpan Raja Madinah, katakanlah kepadanya bahwa aku menginginkan sang putra angunggah (melamar) yang bernama Abdullah. Ingatlah katakanlah permohonanku ini.”

Babu Inya segera undur diri, singkat cerita Inya telah tiba kota raja lalu hendak menghaturkan sembah bakti. Sang inya segera masuk dalam ruang paseban dalem, setelah menghaturkan salam hormat kemudian berkta, "Hamba diutus oleh putri Sayyidina, kepada putra sang prabu supaya ing ngunggah (dimalar) oleh gusti hamba

Ialah sang putra yang bernama Abdullah." Maka Sang Raja berkata, "Sipakah namanya yang menginginkan putraku?" Sang Inya menghatur memberitahu nama gustinya adalah Pratimah. Sang Raja menyambung sabda, "Abdullah putraku itu, tetapi ia sudah menikah. Namun tak patut berumah tangga, istrinya elik (menolak hubungan suami istri). Terlukiskan dalam qalbuku akan nama sang dewi.

(korup) sepertinya sudah lama telah bertemu/mendengar, tetapi wahai putraku, Abdullah. Kamu pergilah ke taman!” Abdullah menghaturkan sembah bakti, kemudian ia pergi ke taman. Sang Inya segera mengikuti langkahnya dari belakang, syadhan sang putri yang telah berada di dalam taman. Ia melihat Abdullah

dari badanya mengeluarkan cahaya bening, bagaikan nyala api tatkala purnama. Bersinar terang benderang, bagaikan bintang mencorong, seperti gurnita gumebyar. 
Matahari mendadak suram terhalangi oleh cahaya nurbuat dari Abdullah, sehingga dalam tamanpun menjadi terang penuh cahaya.

(31)

1. ada di (korup)

2. (korup)

3. (korup)

4. (korup)

5. (korup))

6. (korup)

7. (korup)

8. (korup)

9. (korup)

(32) (korup)

(33) (korup

(34)

1. kepada jeng andika di (korup)

2. (korup)

3. (korup)

4. (korup)

5. (korup)

6. (korup)

7. (korup)

8. (korup)

9. (korup)

10. (korup)

(35) 
1. Putri adi linuwih berkelilinglah ke seluruh penjuru negara

2. (korup) rupa sepertimu, seperti bidadari

3. (korup) dalam hati (korup)

4. (korup)

5. (korup) bunga (korup)

6. (korup)

7. (korup)

8. (korup)

9. (korup)

10. (korup)

\section{TAMAT}

\section{Kesimpulan}

Naskah Gandoang adalah naskah yang ditemukan di Kebuyutan Gandoang. Meskipun cukup kabur, diperkirakan bahwa naskah ini ditulis oleh Ki Milu, seseorang yang memiliki hubungan erat dengan sejarah kekuasaan dan politik di Ciamis - Galuh. Jumlah halaman Naskah Gandoang adalah 35 halaman isi dan 2 halaman kosong. Ukuran naskah 15,5 x 12,2 cm, sedangkan ukuran teksnya adalah $12 \times 9 \mathrm{~cm}$. Jumlah baris teks pada tiap halaman dibagian depan sebanyak 10 baris dan beberapa halaman akhir berisi 6 baris. Naskah Gandoang ini juga tidak memiliki nomor halaman yang asli. Bahasa dalam teks Naskah Gadoang ini adalah bahasa Jawa, sedangkan untuk aksaranya adalah Aksara Jawa (Cacarakan). Jenis bahan naskah (alas naskah) menggunakan kertas daluwang yang terlihat sudah berwarna coklat kehitaman. Kondisi fisik naskah sudah rusak. Teks yang disajikan ini berbicara tentang surat (layang, nawala) yang ditulis oleh Susuhunan Senapati Ing Ngalaga kepada Mas Putu atau Mas Putra Imbanagara agar menduduki, 
memangku, dan mengurusi Galuh (gaduhi bumi galuh (hlm.02), yang memiliki wilayah Galuh. Layaknya sebuah naskah yang lengkap dan utuh, naskah ini memuat sebuah titi mangsa (penanggalan) atas sebuah penulisan layang (surat) yang dikirimkan oleh Susuhunan Ing Ngalaga kepada Mas Putra Imbanagara.

Terdapat tiga pengirim surat dalam naskah Gandoang ini, yaitu: Eyang Raja Desa, Eyang Wiranangga, dan Susuhunan Senapati Ing Ngalaga. Sosok yang bernama Eyang Raja Desa dan Eyang Wiranangga dalam surat tersebut merupakan pemimpin lokal yang memiliki kekuasaan di wilayah Priangan Timur, sedangkan untuk sosok Susuhunan Senapati Ing Ngalaga ia adalah Sultan Agung, Raja Mataram yang paling terkenal. Surat dari Eyang Raja Desa dan Eyang Wiranangga ditujukan kepada Mas Putu (Putra) Imbanagara. Sementara itu, surat Susuhunan Senapati Ing Ngalaga tujuannya adalah Sang Asar. Meskipun sosok pengirim dan penerima masing-masing surat itu berbeda, ternyata titi mangsa (penanggalan) ketiga surat tersebut sama, yaitu bertanggalkan pada hari Kamis tanggal 3 Syawal tahu He yang jika dikonversikan maka bertanggal 22 Maret 1635. 


\section{Daftar Pustaka}

Atja. 1986. Carita Purwaka Caruban nagari: Karya Sastra sebagai Sumber Pengetahuan Sejarah, Proyek Pengembangan Permuseuman Jawa Barat, 1986.

Ekadjati, Edi S. 1983. Naskah Sunda Lama. Kelompok Cerita Pusat Pembinaan dan Pengembangan Bahasa Departemen Pendidikan dan Kebudayaan Republik Indonesia, Jakarta.

Ekadjati, Edi S. 1988. Naskah Sunda: Inventarisasi dan Pencatatan, (Bandung: Universitas Padjajaran.

Departemen Pendidkan dan Kebudayaan Nasional RI, 1990. Kamus Besar Bahasa Indonesia, Balai Pustaka.

Fathurrahman, Oman, dkk., 2010. Filologi dan Islam Indonesia, Kemenag RI Badan Litbang dan Diklat Puslitbang Lektur Keagamaan, Jakarta.

Raffles, Thomas Stamford, 2008. The History of Java, Alih Bahasa oleh Eko Prasetyoningrum, Nuryati Agustin, dan Idda Qoryati mahbubah, Narasi.

Karsono, Karsono H. Saputra, Amyrna Leandra Saleh dan Yudhi Irawan, 2010. Naskah Naskah Pesisiran. Perpustakaan Nasional RI.

Mardiwarsito, L., 1978. Kamus Jawa Kuna (Kawi) - Indonesia. Nusa Indah, Percetakan Ende - Plores.

Sudjana, T. D., Sudibjo, Z. H., 1980. Carub Kandha Carang Seket. Departemen Pendidikan dan Kebudayaan - Proyek Penerbitan Buku Sastra Indonesia dan Daerah, Jakarta.

Sulendraningrat, P. S. Babad Tanah Sunda / Babad Cirebon, tanpa tahun, tanpa penerbit. 
Sulendraningrat, P. S., 1985. Sejarah Cirebon, PN Balai Pustaka, Jakarta.

Sumarlina, Elis Suryani Nani. 2012. Filologi. Bogor: Ghalia Indonesia.

Wahju, Amman N., 2005. Sajarah Wali Syekh Syarif Hidayatullah Sunan Gunungjati (Naskah Mertasinga). Pustaka, Bandung.

Wahju, Amman N., 2007. Sajarah Wali Syekh Syarif Hidayatullah Sunan Gunungjati (Naskah Kungingan). Pustaka, Bandung.

Zoetmulder, P.J., 1995. Kamus Jawa, bekerja sama dengan S.O. Robson diterjemahkan oleh Darusuprapta dan Sumarti Suprayitna. PT. Gramedia Pustaka Utama, Jakarta. 
Muhamad Mukhtar Zaedin

168 | TamaddunVol. 7 , No. I, Januari - Juni 2019 